\title{
Optimization of Parameters of Plastic Lined Pump Structural Based on Fluidsolid Coupling Analysis
}

Lei Xiong ( $\sim 2200120175 @ s t u . a h p u . e d u . c n)$

Anhui Polytechnic University https://orcid.org/0000-0001-8986-7871

\section{Lingfeng Tang}

Anhui Polytechnic University

\section{Bingxue Xu}

Anhui Polytechnic University

\section{Original Article}

Keywords: plastic lined pump, CFD, orthogonal experiment, range analysis, genetic algorithm, parameter optimization, fluidsolid coupling

Posted Date: August 6th, 2021

DOl: https://doi.org/10.21203/rs.3.rs-753334/v1

License: @ (i) This work is licensed under a Creative Commons Attribution 4.0 International License. Read Full License 


\title{
Optimization of Parameters of Plastic Lined Pump Structural based on Fluidsolid Coupling Analysis \\ Lei Xiong, Lingfeng Tang, Bingxue Xu
}

College of Mechanical Engineering, Anhui Polytechnic University, Wuhu, Anhui 241000, China

Correspondence should be addressed to Lei Xiong; 2200120175@stu.ahpu.edu.cn

\begin{abstract}
The main objective of the present article was to obtain the optimum structure of the plastic lined pump under the condition of fluid-structure interaction. The structural parameters of the pump were calculated according to the given design parameters. The three-dimensional geometric model was established. The flow field analysis was carried out by CFD. The inlet diameter $D_{j}$, outlet width $b_{2}$, vane outlet angle $\beta_{2}$ and vane number $Z$ of the impeller were selected as the four factors to design orthogonal experiment. The results were analyzed by range analysis. The efficiency and NPSH were obtained as combined parameters under the evaluation index. The genetic algorithm was used to optimize its structural parameters, and the best structural combination parameters of the plastic-lined pump under the conditions of maximum efficiency and minimum cavitation were obtained. The efficiency was increased by $2.78 \%$ and the NPSH was reduced by 0.249707 after optimization. Finally, the stress distribution and displacement deformation under the condition of the coupling field were obtained by the fluidsolid coupling analysis. The maximum stress was $4.83 \mathrm{mpa}$ and the maximum displacement deformation was $3.1547 \mathrm{e}-5 \mathrm{~m}$.
\end{abstract}

Key Words: plastic lined pump, CFD, orthogonal experiment, range analysis, genetic algorithm, parameter optimization, fluidsolid coupling

\section{Introduction}

With the rapid development of industry and agriculture in our country, the traditional metal pumps are often difficult to meet the requirements of corrosion resistance, besides that, some special metal cost is higher. So, the appearance of plastic lined pump solved these problems in time. Compared with other kinds of pumps, plastic lined pumps are widely used for their excellent corrosion resistance. 
In the process of scientific and engineering case analysis, there is usually no absolute singlefield problem, and most physical phenomena are coupled with each other ${ }^{[1]}$. For the plastic lined pump, fluid-structure coupling is the interaction between the flow field and the structure of the pump body. The internal running state of pump is very complex on account of the fluidsolid coupling and the process of conveying medium. Therefore, it is urgent to study the plastic lined pump from the perspective of multi physical field coupling ${ }^{[2]}$. The method of fluidsolid coupling is closer to the actual operation of the plastic lined pump than the traditional ones. Its novelty stems from the fact it takes into account the turbulence modeling and at the same time the strong-coupling of fluid and structure ${ }^{[3]}$. The fluid-structure-interaction (FSI) technology makes the coupling analysis of flow field and structure field become a reality, which makes it possible to study the fluid structure interaction of pump.

Researchers mainly focus on the single-stage and multi-stage metal centrifugal pump, but less on plastic lined centrifugal pump. Such as the distribution of the internal flow field of plastic lined pump, the stress of fluid structure coupling during operation, the situation and location of cavitation damage in the plastic lined pump, and the deformation and displacement of the impeller under the action of fluid-solid coupling have not been studied. Therefore, it is necessary to study the internal flow field and fluid structure coupling of plastic lined pump.

In this paper, CFD is used to analyze the flow field of the lining plastic pump. Through orthogonal experiment and range analysis, it can be concluded that the efficiency and NPSH are taken as the combined parameters under the evaluation index. The genetic algorithm is used to optimize the structural parameters of the plastic lined pump, and the optimal parameter combination is obtained. Based on ANSYS Workbench, the structural change of the impeller under the effect of fluidsolid coupling is obtained.

\section{Structure Design}

Because of their outstanding corrosion resistance, light weight and low price, plastic lined pumps are widely used in various fields of national economic production. Plastic lined parts, with the help of forming mold, are lined with a layer of plastic in the metal shell. On the one hand, it can effectively prevent the corrosion of the medium. On the other hand, the strength of the metal shell can support the weight of the plastic centrifugal pump itself, the pressure of some pipes and various vibration forces during operation. This design combines the strength of the metal and the 
corrosion resistance of the plastic and its market ownership is increasing day by day.

The basic parameters of the lining plastic pump are as follows: flow rate $Q=100 \mathrm{~m}^{3} / \mathrm{h}$, head $\mathrm{H}=80 \mathrm{~m}$, rotate speed $\mathrm{n}=2900 \mathrm{rpm}$, inlet diameter of impeller $D_{j}=90 \mathrm{~mm}$, outlet diameter $D_{d}=80$ mm, width of impeller inlet $b_{1}=18 \mathrm{~mm}$, outlet width $b_{2}=10 \mathrm{~mm}$, impeller inlet angle $\beta_{1}=20^{\circ}$, outlet angle $\beta_{2}=30^{\circ}$, and the wrap angle $\varphi=110^{\circ}$. According to the above parameters, the physical model of impeller and the volute-type discharge passage was established ${ }^{[4]}$, as shown in Figure 1.

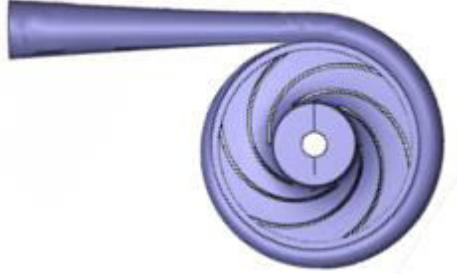

FIGURE 1: Fluid domain model.

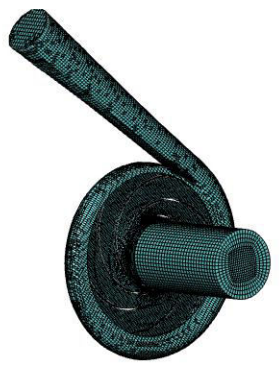

FIGURE 2: Mesh generation.

\section{Flow Field Simulation}

Build 3D model by CFturbo10.0 and simulate by PumpLinx. After the impeller and volute were imported into PumpLinx, an inlet section needed to be established at the entrance of the impeller. Then the inlet section, impeller and volute were meshed, as shown in Figure 2.

Here, the iterative steps of the plastic lined pump were set as 1000 steps. Figure 3 shows the convergence of the iterative residual curve.

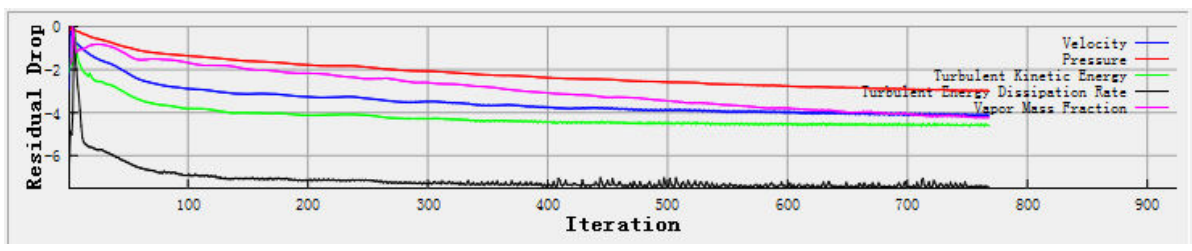

FIGURE 3: Residual curve

Figure 4 is a speed distribution diagram of the lining plastic pump ${ }^{[4]}$. It shows that the velocity inside the impeller of the plastic lined pump was generally symmetrical. The closer the impeller was to the edge, the higher the velocity was. Besides, the velocity on the working face of the impeller was greater than that on the back of the vane with the same diameter. 


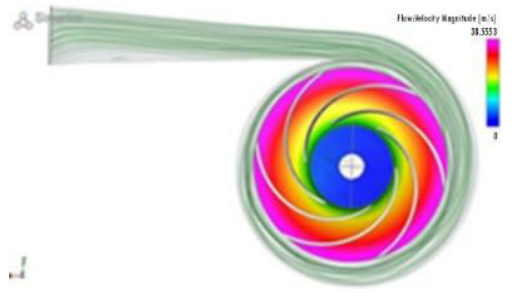

FIGURE 4: Velocity cloud diagram.

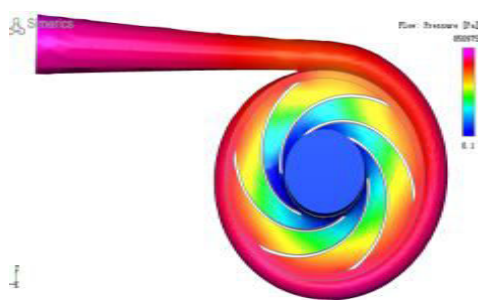

Figure 5: Pressure cloud diagram.

Figure 5 shows the pressure distribution of the lining plastic pump. The pressure was increasing gradually from the inlet of the impeller to its outlet ${ }^{[4]}$. The pressure field inside the impeller was axisymmetric. There was no obvious mutation area between the impeller and the volute channel. In addition, the pressure near the impeller inlet was the lowest. Due to the pressure difference, this area is also most prone to cavitation.

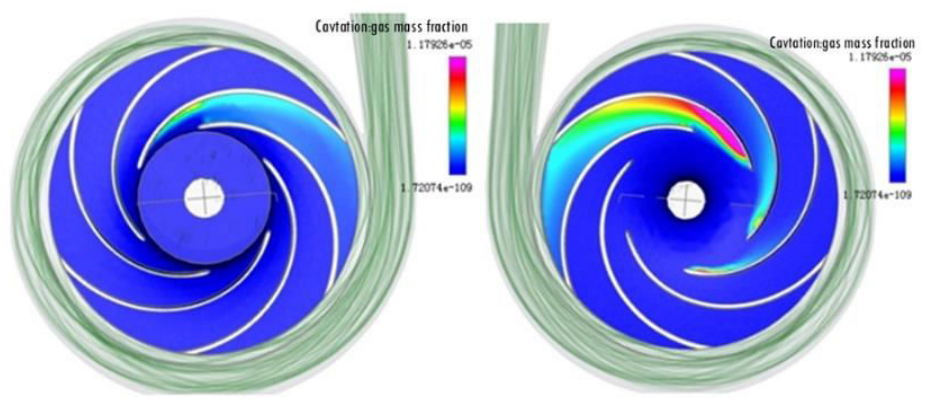

FIGURE 6: Gas mass fraction diagram.
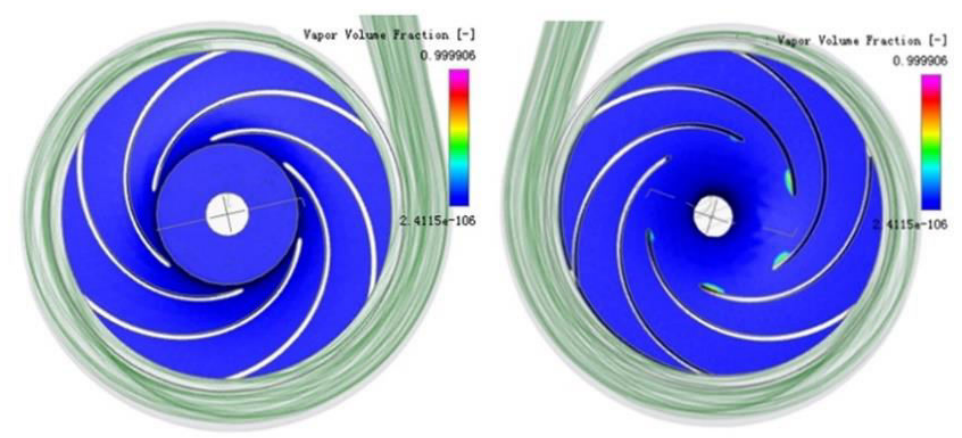

FIGURE 7: Gas volume fraction diagram.

In this paper, the gas mass fraction and gas volume fraction inside the plastic-lined pump are used to express the degree of cavitation. The higher the gas mass fraction and gas volume fraction are, the more serious the cavitation is.

Figure 6 shows that the gas mass fraction of the pump was $1.7926 \times 10^{-5}$ after reaching stable convergence and cavitation mainly occurred in the back area of the blade above the tongue, there was slight cavitation at the head of other blades, too. Combined with the analysis of the pressure 
cloud diagram in Figure 5, the prediction of the cavitation location was also verified. Figure 7 shows that the gas volume fraction of the impeller is as high as 0.999906. Since the fluid medium set by the boundary conditions is water, it means that the medium has reached the critical pressure of vaporization in this operating state. Especially, the medium itself is also a certain gas content, so the fluid medium evaporates rapidly. A large number of vapor bubbles were generated, which results in a relatively high gas volume fraction and brings cavitation damage to the plastic-lined pump.

When the internal flow field of the plastic-lined pump is stable, its internal speed, pressure, etc. also tend to be stable. At this time, the working efficiency of the plastic-lined pump can be calculated according to formulas (1) and (2).

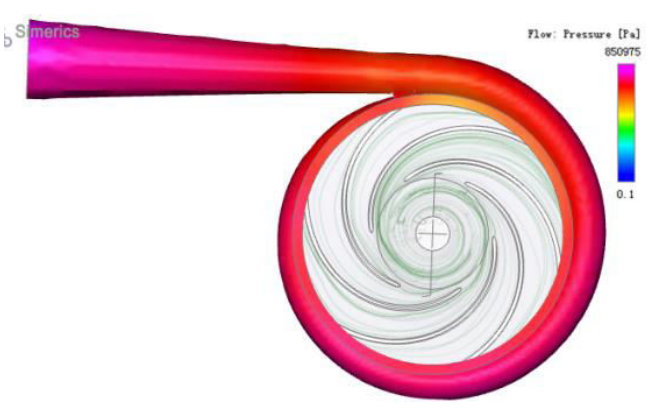

FIGURE 8: Outlet pressure diagram.

It can be seen from Figure 8 that the outlet pressure of the plastic lined pump was 850975pa. Because the inlet pressure of the boundary condition was set as $101325 \mathrm{pa}$, the pressure difference between the inlet and outlet was:

$$
\Delta P=P_{\text {outlet }}-P_{\text {inlet }}=784012 \mathrm{~Pa}
$$

According to the efficiency calculation formula of the pump:

$$
\begin{gathered}
H=\frac{\Delta P}{\rho g} \\
\eta=\frac{Q}{1000 P} \Delta P
\end{gathered}
$$

Where $\rho$ is the density of fluid medium $(\mathrm{kg} / \mathrm{m} 3) ; g$ is the gravitational acceleration; $\eta$ is the efficiency; $P$ is the shaft power; $\Delta P$ is the pressure difference between pump inlet and outlet.

Calculated:

$$
\eta=\frac{Q}{1000 P} \Delta P=68.79 \%
$$




\section{Orthogonal Experiment and Range Analysis}

\subsection{Orthogonal Experiment}

In this paper, the efficiency and cavitation of the plastic lined pump were selected as the evaluation indexes of the orthogonal test. The inlet diameter $D_{j}$, outlet width $b_{2}$, vane outlet angle $\beta_{2}$ and vane number $Z$ were selected as the four factors of the orthogonal test, which were respectively represented by A, B, C and D. Each factor was set with five levels, as shown in Table 1.

Table 1: Factor-level table of orthogonal test

\begin{tabular}{ccccc}
\hline Factor & $\mathrm{A}(\mathrm{mm})$ & $\mathrm{B}(\mathrm{mm})$ & $\mathrm{C}\left({ }^{\circ}\right)$ & $\mathrm{D}$ \\
\hline Level 1 & 80 & 6 & $26^{\circ}$ & 4 \\
Level 2 & 86 & 8 & $28^{\circ}$ & 5 \\
Level 3 & 90 & 10 & $30^{\circ}$ & 6 \\
Level 4 & 94 & 12 & $32^{\circ}$ & 7 \\
Level 5 & 98 & 14 & $34^{\circ}$ & 8 \\
\hline
\end{tabular}

For the orthogonal experiment with five levels of four factors, the orthogonal table that could selected is $L_{25}\left(5^{4}\right)^{[4]}$. 25 groups of experimental data obtained from orthogonal test were simulated to obtain the gas volume fraction under each group of parameters. The centrifugal pump efficiency of corresponding groups was calculated by equations (1) and (2), as shown in Table 2.

Table 2: Orthogonal experimental results

\begin{tabular}{ccccccc}
\hline sequence & A & B & C & D & efficiency & $\begin{array}{c}\text { NPSH } \\
\text { (Gas volume } \\
\text { fraction })\end{array}$ \\
\hline 1 & 80 & 6 & 26 & 4 & 63.22 & 0.978067 \\
2 & 80 & 8 & 28 & 5 & 64.86 & 0.973542 \\
3 & 80 & 10 & 30 & 6 & 63.78 & 0.962341 \\
4 & 80 & 12 & 32 & 7 & 65.26 & 0.988031 \\
5 & 80 & 14 & 34 & 8 & 64.95 & 0.960375 \\
6 & 86 & 8 & 28 & 6 & 63.22 & 0.971398 \\
7 & 86 & 8 & 30 & 7 & 64.16 & 0.961674 \\
8 & 86 & 10 & 32 & 8 & 65.58 & 0.967709 \\
9 & 86 & 12 & 34 & 4 & 62.54 & 0.959413 \\
10 & 86 & 14 & 26 & 5 & 64.36 & 0.980602 \\
11 & 90 & 6 & 30 & 8 & 62.11 & 0.991571 \\
12 & 90 & 8 & 32 & 4 & 62.55 & 0.980605 \\
13 & 90 & 10 & 34 & 5 & 63.47 & 0.961259 \\
14 & 90 & 12 & 26 & 6 & 65.29 & 0.955471
\end{tabular}




\begin{tabular}{lcccccc}
15 & 90 & 14 & 28 & 7 & 67.34 & 0.971307 \\
16 & 94 & 6 & 32 & 5 & 68.17 & 0.963179 \\
17 & 94 & 8 & 34 & 6 & 63.35 & 0.988036 \\
18 & 94 & 10 & 26 & 7 & 66.79 & 0.973451 \\
19 & 94 & 12 & 28 & 8 & 65.31 & 0.969079 \\
20 & 94 & 14 & 30 & 4 & 62.96 & 0.960571 \\
21 & 98 & 6 & 34 & 7 & 66.28 & 0.964084 \\
22 & 98 & 8 & 26 & 8 & 64.05 & 0.977471 \\
23 & 98 & 10 & 28 & 4 & 63.16 & 0.979361 \\
24 & 98 & 12 & 30 & 5 & 65.03 & 0.965464 \\
25 & 98 & 14 & 32 & 6 & 69.21 & 0.955461 \\
\hline
\end{tabular}

\subsection{Range analysis}

(1) Analysis of the influence trend of various factors on efficiency

The larger the value of $\mathrm{R}$ is, the greater the influence of this factor on the test evaluation index is. Table 3 shows that the order of the influence of each test factor on the efficiency of the evaluation index is: $\mathrm{D}>\mathrm{A}>\mathrm{B}>\mathrm{C}$, namely: vane number $>$ inlet diameter $>$ outlet width $>$ vane outlet angle. The influence trend of various factors on efficiency is shown in Figure 9. According to the highest efficiency evaluation index, the best combination of structural parameters can be obtained as A5B5C4D3, that is, when the inlet diameter $D_{j}$ was $98 \mathrm{~mm}$, the outlet width $b_{2}$ was $14 \mathrm{~mm}$, the vane outlet angle $\beta_{2}$ was $32^{\circ}$ and the number of vanes $\mathrm{Z}$ was 6 , the maximum efficiency value can be obtained. Representatively, this group of parameters is included in 25 groups of test data. The new tests results are shown in Figure 10 and Figure 11.

Table 3: Influence data of various factors on efficiency

\begin{tabular}{ccccc}
\hline & $\mathrm{A}$ & $\mathrm{B}$ & $\mathrm{C}$ & $\mathrm{D}$ \\
\hline K1 & 322.07 & 323 & 323.71 & 314.43 \\
K2 & 319.86 & 318.97 & 323.89 & 325.89 \\
K3 & 320.76 & 322.78 & 318.04 & 324.85 \\
K4 & 326.58 & 323.43 & 330.77 & 329.83 \\
K5 & 327.73 & 328.82 & 320.59 & 322 \\
k1 & 64.414 & 64.6 & 64.742 & 62.886 \\
k2 & 63.972 & 63.794 & 64.778 & 65.178 \\
k3 & 64.152 & 64.556 & 63.608 & 65.966 \\
k4 & 65.316 & 64.686 & 66.154 & 64.97 \\
k5 & 65.546 & 65.764 & 64.118 & 64.4 \\
R & 1.132 & 1.078 & 0.036 & 1.514 \\
Sequencing & 5 & 5 & 4 & 3 \\
\hline
\end{tabular}




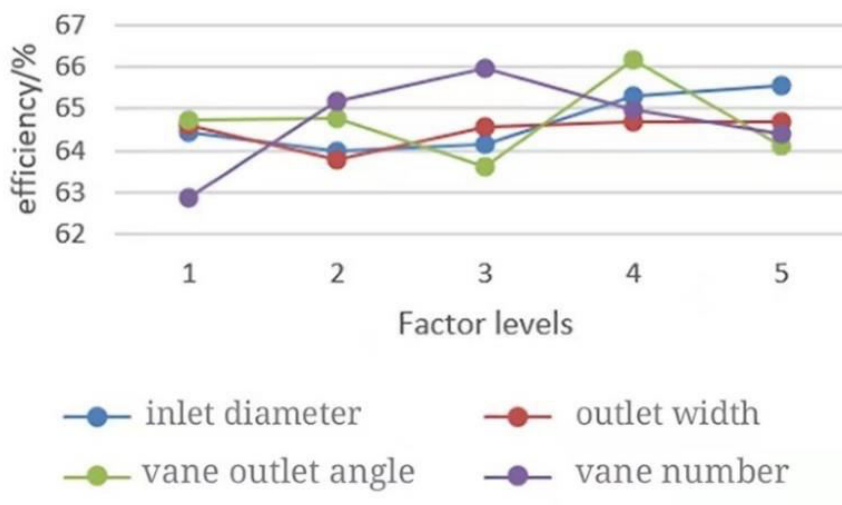

FIGURE 9: Influence trend of each parameter on efficiency.

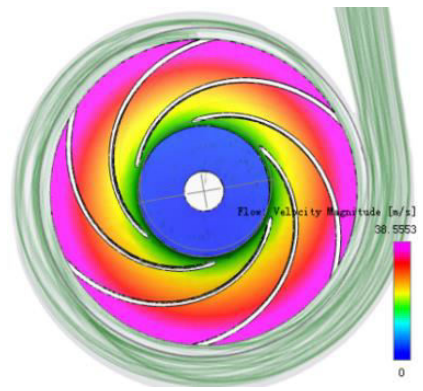

FigURE 10: Velocity cloud (new)

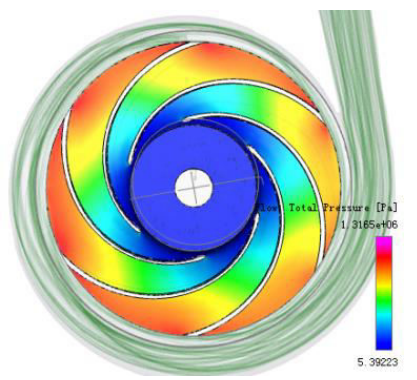

FigURE 11: Pressure cloud (new)

(2) Analysis of Influence Trend of Various Factors on Cavitation Erosion.

According to the range value $\mathrm{R}$, the order of the influence of each parameter on the cavitation is: $\mathrm{B}>\mathrm{D}>\mathrm{C}>\mathrm{A}$, namely: outlet width $>$ vane number $>$ vane outlet angle $>$ inlet diameter. The influence trend of various factors on cavitation is shown in Figure 12. It can be seen from Table 4 that according to the evaluation index of the smallest cavitation damage (the smallest gas volume fraction), the best combination of structural parameters can be obtained as A1B2C1D4, that is, when the inlet diameter $D_{j}$ was $80 \mathrm{~mm}$, the outlet width $b_{2}$ was $8 \mathrm{~mm}$, the vane outlet angle $\beta_{2}$ was $26^{\circ}$ and the vane number $\mathrm{Z}$ was 7 , the gas volume fraction was the minimum. The optimized structural parameters of the plastic lined pump were not in the existing tests ${ }^{[4]}$. The CFD software was used to remodel and verify the test results ${ }^{[4]}$, As shown in Figure 13, the minimum gas volume fraction of this group was 0.90108 . Significantly, the cavitation damage was reduced.

Table 4: Influence data of various factors on cavitation.

\begin{tabular}{ccccc}
\hline & $\mathrm{A}$ & $\mathrm{B}$ & $\mathrm{C}$ & $\mathrm{D}$ \\
\hline $\mathrm{K} 1$ & 4.862356 & 4.868299 & 4.865062 & 4.858017 \\
$\mathrm{~K} 2$ & 4.840796 & 4.870127 & 4.864687 & 4.844046 \\
$\mathrm{~K} 3$ & 4.860213 & 4.844121 & 4.841621 & 4.832707 \\
$\mathrm{~K} 4$ & 4.854316 & 4.837458 & 4.854985 & 4.858547 \\
$\mathrm{~K} 5$ & 4.841841 & 4.828316 & 4.833167 & 4.866205 \\
$\mathrm{k} 1$ & 0.9724712 & 0.9736598 & 0.9730124 & 0.9716034 \\
k2 & 0.9681592 & 0.9740254 & 0.9729374 & 0.9688092 \\
k3 & 0.9720426 & 0.9688242 & 0.9683242 & 0.9665414
\end{tabular}




\begin{tabular}{lcccc} 
k4 & 0.9708632 & 0.9674916 & 0.970997 & 0.9717094 \\
k5 & 0.9683682 & 0.9656632 & 0.9666334 & 0.973241 \\
R & 0.004312 & 0.0083622 & 0.006379 & 0.0066996 \\
uencing & 1 & 2 & 1 & 4 \\
\hline
\end{tabular}

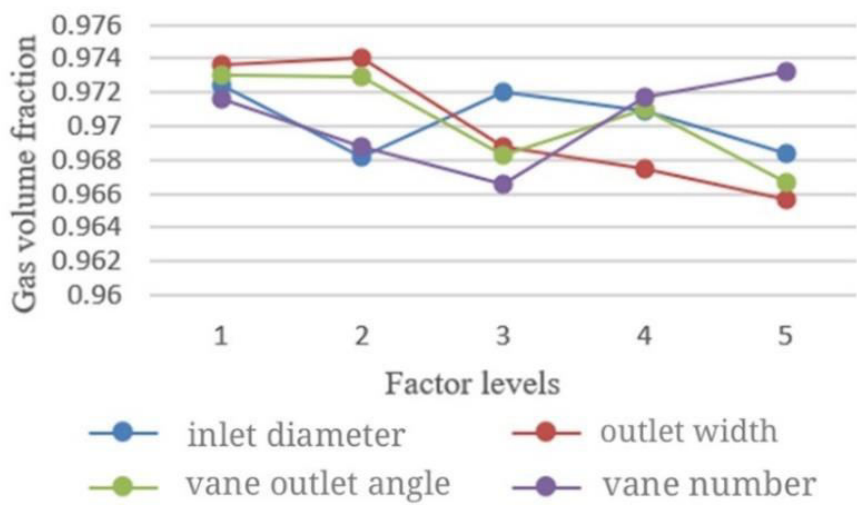

FIGURE 12: Influence trend of each parameter on gas volume fraction.
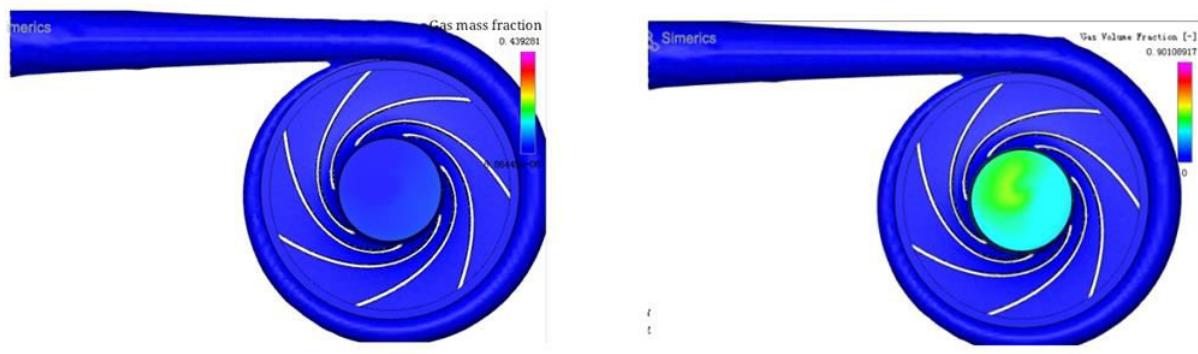

FIGURE 13: Gas mass fraction and gas volume fraction (new)

\section{Multi objective optimization design of impeller structure parameters}

Based on the traditional design experience and CFD analysis of centrifugal pump, it is necessary to further optimize the structural parameters of centrifugal pump. In this chapter, taking the minimum efficiency loss and cavitation damage of plastic lined pump as the optimization objective, the mathematical optimization model was established. After dealing with the relationship between the objective function and the constraint conditions, the multi-objective optimization was carried out based on MATLAB and genetic algorithm. The optimal structure parameter combination of plastic lined pump performance was obtained.

\subsection{Principle of genetic algorithm}

Genetic algorithm (GA) is a kind of random optimization search method based on the evolution law of biology. It starts with a population that represents the potential solution set of the problem. A population is composed of a certain number of individuals encoded by genes and each 
individual is actually an entity with chromosome characteristics. As the main carrier of genetic material, chromosome is the collection of multiple genes, which determines the external performance of individual shape.

Due to its complexity, imitating gene coding is often simplified, such as binary coding. After the emergence of primitive population, generations of evolution have produced better and better approximate solutions according to the survival principle of survival of the fittest. In each generation, individuals were selected on the basis of the fitness of the individuals in the problem domain. They combined, crossed and mutated with the help of the genetic operators of natural genetics to produce the population representing the new solution set. This process will lead to the later generation population to be more adaptive to the environment than the previous generation. The optimal individual in the last generation population can be used as the approximate optimal solution of the problem after decoding.

\subsection{Optimization and calculation of genetic algorithm}

Genetic algorithm toolbox was used for objective optimization. Input calculation formula, set population size to 1000 , population to 1000 , stall generations to 1000 and function tolerance to 1e-3, genetic toolbox began to calculate and solve. Then the iterative optimization diagram and optimization results were obtained, as shown in figure 14 and figure 15.

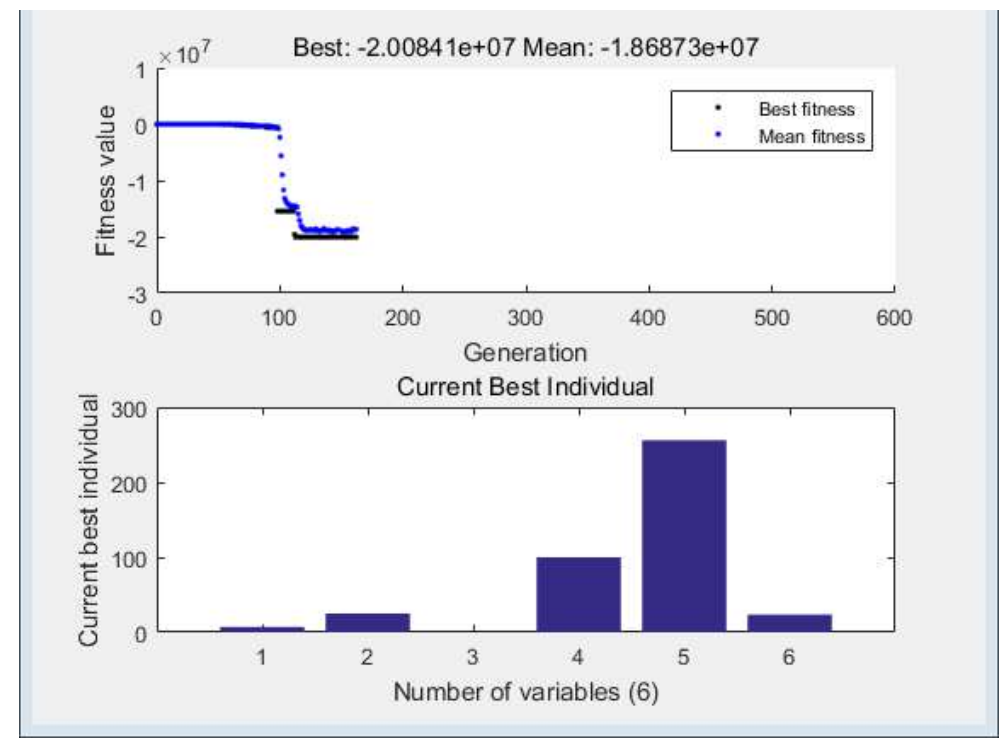

FIGURE 14: Iterative convergence graph. 


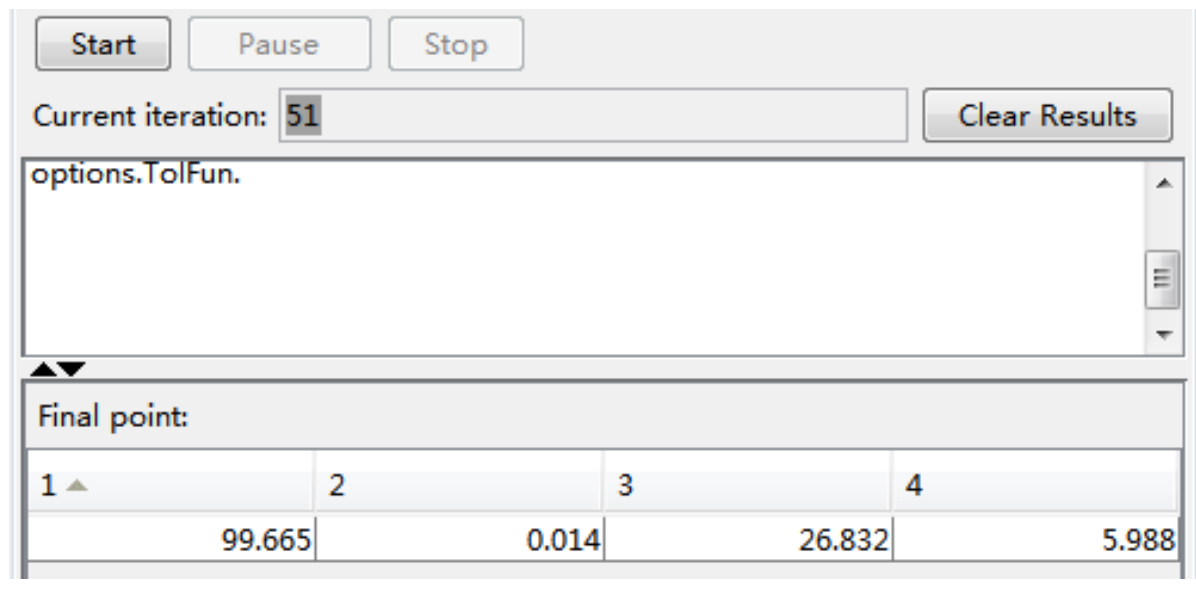

FIGURE 15: Calculation results.

The parameters of the final optimization results after rounding are shown in Table 5.

Table 5: Optimization results

\begin{tabular}{ccccc}
\hline Parameter & $\mathrm{D}_{\mathrm{j}}$ & $\mathrm{b}_{2}$ & $\beta_{2}$ & $\mathrm{Z}$ \\
\hline Before optimization & 90 & 10 & 30 & 6 \\
After optimization & 100 & 14 & 27 & 6 \\
\hline
\end{tabular}

Use the optimized parameters to perform three-dimensional modeling of the plastic-lined pump again, and import the new model into PumpLinx for flow field analysis. As shown in Figure 16 , the outlet pressure of the plastic lined pump was $885337 \mathrm{~Pa}$, the efficiency of the pump can be calculated as $71.57 \%, 2.78 \%$ higher than the previous $68.79 \%$. As shown in Figure 17, the gas volume fraction was increased from the previous 0.999906 to 0.750199 , reduced by 0.249707 . The overall performance of plastic lined pump had been improved.

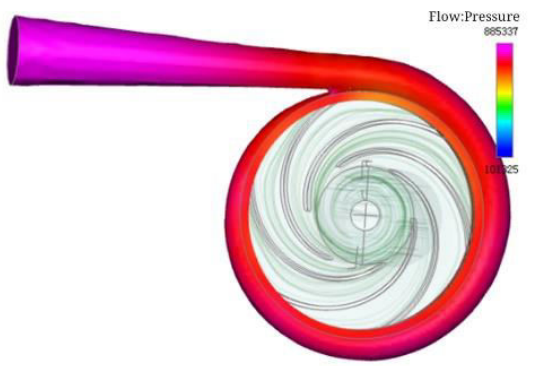

FIGURE 16: Outlet pressure.

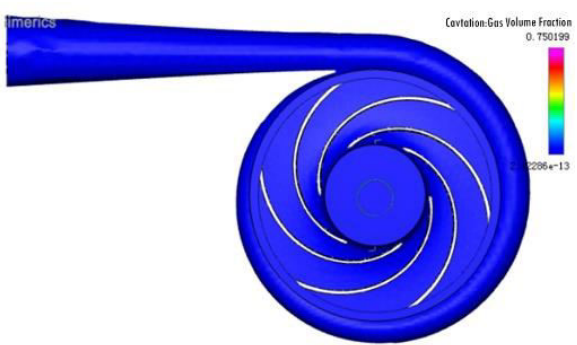

FIGURE 17: Gas volume fraction.

\section{Structural analysis based on fluid structure coupling}

Impeller is the core component of plastic lined pump and its structure design directly affects the performance of plastic lined pump. In this paper, ANSYS Workbench was used to analyze the fluid structure coupling of the impeller of the plastic lined pump, which is closer to the essence of 
the operation of the pump. (Note: the material of plastic lined pump impeller is polyethylene)

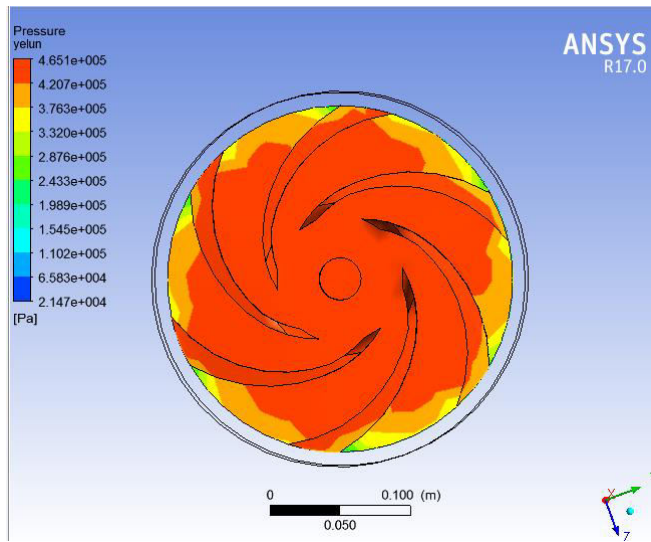

FIGURE 18: Distribution of water pressure.

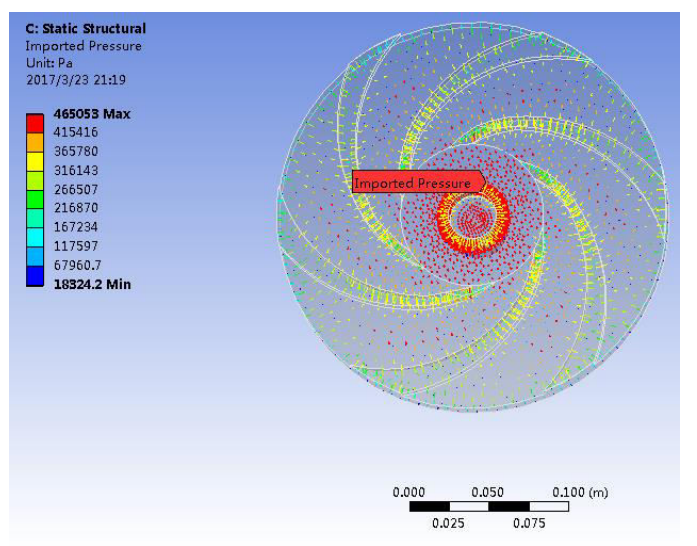

FIGURE 19: Pressure loading.

It can be seen from Figure 18 that the equivalent stress under the flow field load of impeller was axisymmetric. There was no obvious abrupt change of the distribution of pressure in each channel. Besides those, the maximum pressure was at the impeller inlet and the pressure at the impeller outlet decreased gradually. At the same radius, the pressure of the working face of vane was larger than that of the back area. Figure 19 shows that the closer the impeller was to the center, the greater the pressure was. Pressure comes mainly from the action of fluid on the impeller surface. The overall distribution of pressure load was also corresponding to the distribution of water pressure in Figure 18.

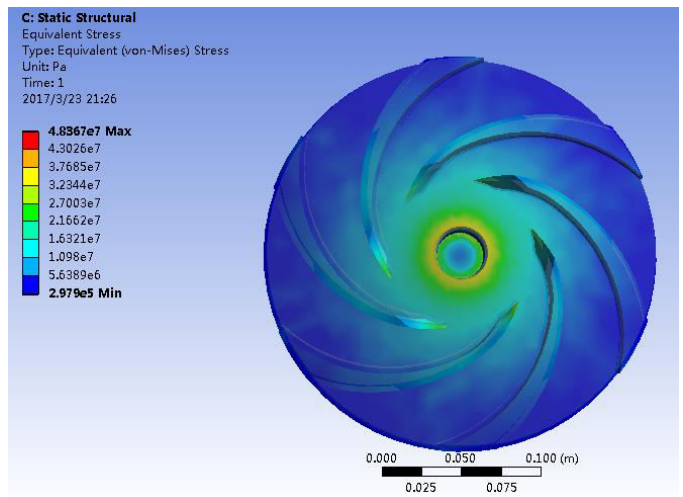

FIGURE 20: Equivalent stress diagram.

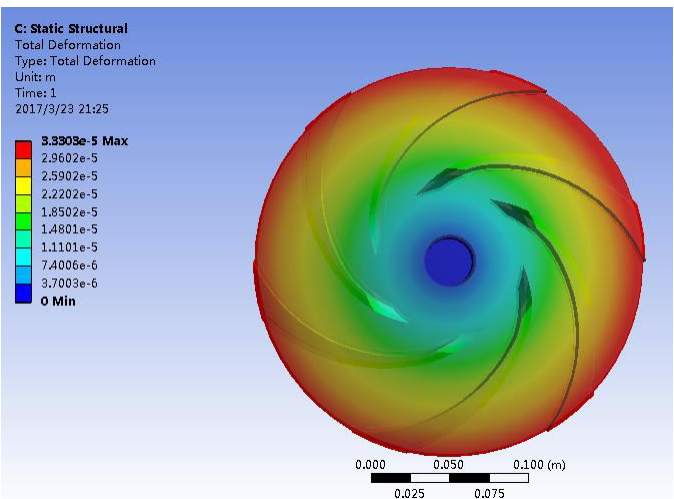

FIGURE 21: Total displacement and deformation.

According to the equivalent stress diagram of the impeller in Figure 20, the equivalent stress on the surface of impeller increased with the decrease of the radius. The maximum equivalent stress was $4.83 \mathrm{MPa}$ in the center area of the impeller. It can be seen from Figure 21 that with the increase of impeller radius, the deformation of impeller increased gradually. It reached the maximum value at the edge of impeller. 


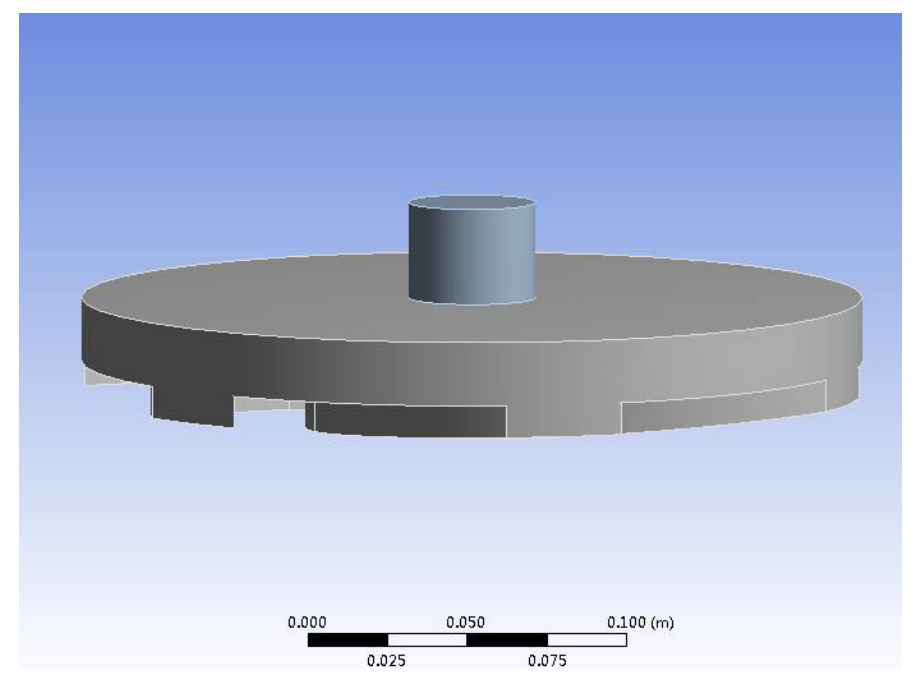

FIGURE 22: Pre-deformation drawing of impeller.

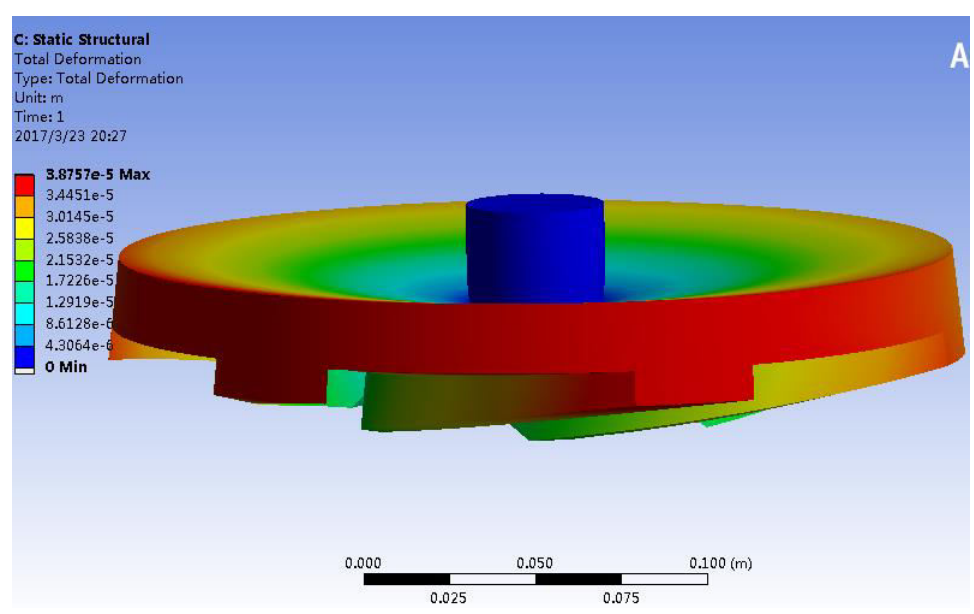

FIGURE 23: Total deformation displacement diagram of impeller.

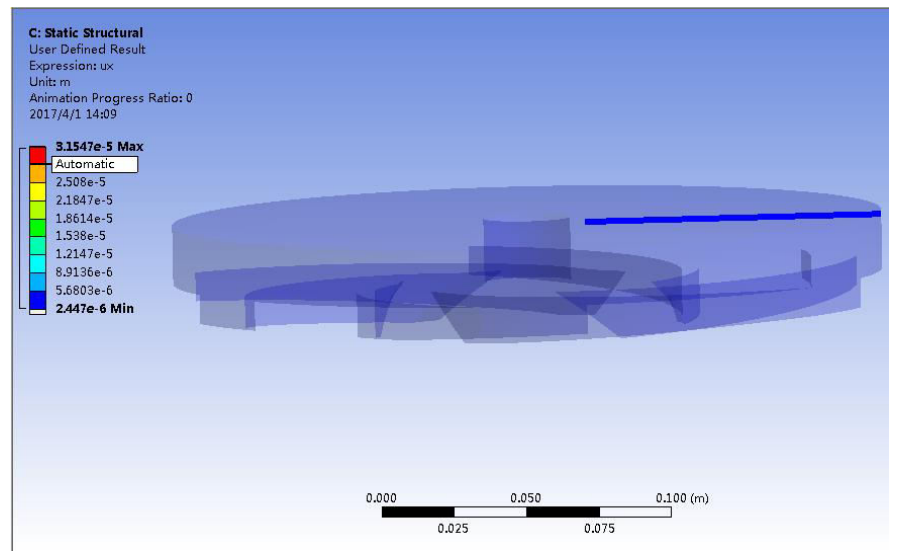

FIGURE 24: Initial diagram of total deformation deflection curve of impeller. 


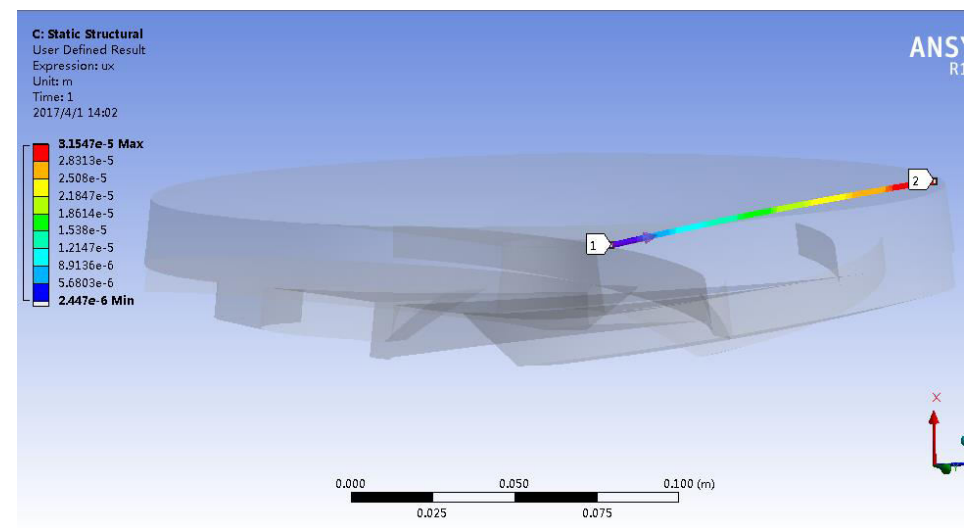

FIGURE 25: Total deformation and deflection curve of impeller.

The Figure 22 and the Figure 23 show that the displacement gradually increased from the impeller inlet to the impeller outlet. The displacement of the edge of impeller was the largest and the displacement of the root was the smallest. For the plastic lined pump, the polyethylene material used in the impeller and volute is weaker than the metal material in terms of wear resistance and compression resistance. Once the impeller wear occurs, the damage degree is far greater than that of the metal pump. In order to obtain the deformation and displacement of each point of the impeller, the deflection curve was established at the center and edge of the impeller, as shown in Figure 24 and Figure 25. The displacement variation of each point on the deflection curve of impeller are shown in Table 6.

Table 6: Displacement of each point of impeller

\begin{tabular}{ccccccccc}
\hline Sequence & $\mathrm{x}(\mathrm{m})$ & $\mathrm{y}(\mathrm{m})$ & Sequence & $\mathrm{x}(\mathrm{m})$ & $\mathrm{y}(\mathrm{m})$ & Sequence & $\mathrm{x}(\mathrm{m})$ & $\mathrm{y}(\mathrm{m})$ \\
\hline 1 & 0 & $2.45 \mathrm{E}-06$ & 18 & $3.63 \mathrm{E}-02$ & $1.40 \mathrm{E}-05$ & 35 & $7.26 \mathrm{E}-02$ & $2.43 \mathrm{E}-05$ \\
2 & $2.14 \mathrm{E}-03$ & $3.10 \mathrm{E}-06$ & 19 & $3.84 \mathrm{E}-02$ & $1.47 \mathrm{E}-05$ & 36 & $7.47 \mathrm{E}-02$ & $2.48 \mathrm{E}-05$ \\
3 & $4.27 \mathrm{E}-03$ & $3.86 \mathrm{E}-06$ & 20 & $4.06 \mathrm{E}-02$ & $1.53 \mathrm{E}-05$ & 37 & $7.69 \mathrm{E}-02$ & $2.54 \mathrm{E}-05$ \\
4 & $6.41 \mathrm{E}-03$ & $4.57 \mathrm{E}-06$ & 21 & $4.27 \mathrm{E}-02$ & $1.60 \mathrm{E}-05$ & 38 & $7.90 \mathrm{E}-02$ & $2.59 \mathrm{E}-05$ \\
5 & $8.54 \mathrm{E}-03$ & $5.28 \mathrm{E}-06$ & 22 & $4.48 \mathrm{E}-02$ & $1.66 \mathrm{E}-05$ & 39 & $8.11 \mathrm{E}-02$ & $2.64 \mathrm{E}-05$ \\
6 & $1.07 \mathrm{E}-02$ & $5.97 \mathrm{E}-06$ & 23 & $4.70 \mathrm{E}-02$ & $1.72 \mathrm{E}-05$ & 40 & $8.33 \mathrm{E}-02$ & $2.70 \mathrm{E}-05$ \\
7 & $1.28 \mathrm{E}-02$ & $6.66 \mathrm{E}-06$ & 24 & $4.91 \mathrm{E}-02$ & $1.79 \mathrm{E}-05$ & 41 & $8.54 \mathrm{E}-02$ & $2.75 \mathrm{E}-05$ \\
8 & $1.49 \mathrm{E}-02$ & $7.34 \mathrm{E}-06$ & 25 & $5.13 \mathrm{E}-02$ & $1.85 \mathrm{E}-05$ & 42 & $8.76 \mathrm{E}-02$ & $2.80 \mathrm{E}-05$ \\
9 & $1.71 \mathrm{E}-02$ & $8.00 \mathrm{E}-06$ & 26 & $5.34 \mathrm{E}-02$ & $1.91 \mathrm{E}-05$ & 43 & $8.97 \mathrm{E}-02$ & $2.85 \mathrm{E}-05$ \\
10 & $1.92 \mathrm{E}-02$ & $8.67 \mathrm{E}-06$ & 27 & $5.55 \mathrm{E}-02$ & $1.97 \mathrm{E}-05$ & 44 & $9.18 \mathrm{E}-02$ & $2.90 \mathrm{E}-05$
\end{tabular}




\begin{tabular}{lllllllll}
11 & $2.14 \mathrm{E}-02$ & $9.35 \mathrm{E}-06$ & 28 & $5.77 \mathrm{E}-02$ & $2.03 \mathrm{E}-05$ & 45 & $9.40 \mathrm{E}-02$ & $2.95 \mathrm{E}-05$ \\
12 & $2.35 \mathrm{E}-02$ & $1.00 \mathrm{E}-05$ & 29 & $5.98 \mathrm{E}-02$ & $2.09 \mathrm{E}-05$ & 46 & $9.61 \mathrm{E}-02$ & $3.00 \mathrm{E}-05$ \\
13 & $2.56 \mathrm{E}-02$ & $1.07 \mathrm{E}-05$ & 30 & $6.19 \mathrm{E}-02$ & $2.15 \mathrm{E}-05$ & 47 & $9.82 \mathrm{E}-02$ & $3.05 \mathrm{E}-05$ \\
14 & $2.78 \mathrm{E}-02$ & $1.14 \mathrm{E}-05$ & 31 & $6.41 \mathrm{E}-02$ & $2.21 \mathrm{E}-05$ & 48 & 0.10036 & $3.10 \mathrm{E}-05$ \\
15 & $2.99 \mathrm{E}-02$ & $1.20 \mathrm{E}-05$ & 32 & $6.62 \mathrm{E}-02$ & $2.26 \mathrm{E}-05$ & 49 & 0.1025 & $3.15 \mathrm{E}-05$ \\
16 & $3.20 \mathrm{E}-02$ & $1.27 \mathrm{E}-05$ & 33 & $6.83 \mathrm{E}-02$ & $2.32 \mathrm{E}-05$ & & & \\
17 & $3.42 \mathrm{E}-02$ & $1.34 \mathrm{E}-05$ & 34 & $7.05 \mathrm{E}-02$ & $2.37 \mathrm{E}-05$ & & & \\
\hline
\end{tabular}

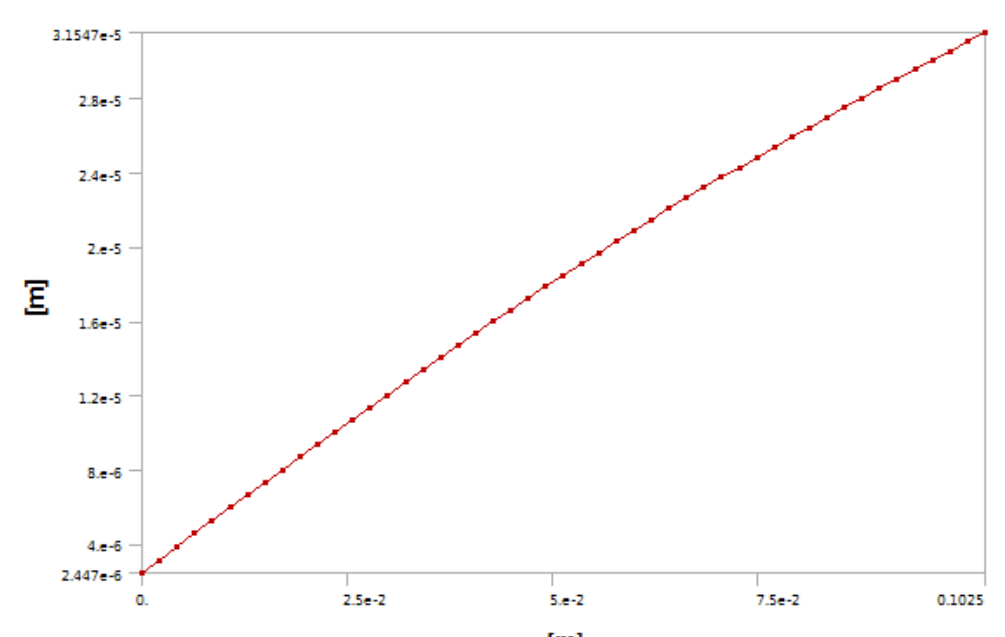

[m]

FIGURE 26: Coordinate diagram of total deformation and deflection curve of impeller.

Figure 26 is the coordinate diagram of total deformation and deflection curve of impeller. Its origin and end point are point 1 and 2 marked in Figure 25. From the coordinate diagram, the displacement of the deformed point 2 relative to the non-deformed position changed by $3.1547 \mathrm{e}-5 \mathrm{~m}$. The deformation of impeller changed linearly from the center to the edge and point 2 is the edge of vane. If the clearance between impeller and pump cover is not designed reasonably, wear will occur in the working process. Therefore, according to the deformation and displacement of the impeller, it is significant to reasonably design the clearance between the impeller and the pump cover and the inlet width of the vortex chamber.

\section{Conclusion}

This paper focuses on improving the efficiency of plastic lined pump and reducing cavitation damage. The internal flow field of plastic lined pump was simulated and analyzed by CFD. Then the optimal structure parameter combination was found based on genetic algorithm. Combined with the actual working condition of plastic lined pump, the fluidsolid coupling method is adopted 
to analyze the stress and structure change of impeller. It has guiding significance for the safety and reliability of the plastic lined pump. The main research results are as follows.

(1) The orthogonal experimental table of $L_{25}\left(5^{4}\right)$ was designed and orthogonal experiment was carried out. In this paper, the best combination parameters of efficiency conditions and cavitation conditions are obtained respectively.

(2) This paper uses genetic algorithm to find the best combination of structural parameters. Based on ANSYS Workbench, the fluidsolid coupling calculation method, which is closer to the essence of impeller operation, was adopted to analyze the stress and structure change.

\section{Reference}

[1] Xiuli Wang, Yonggang Lu, Rongsheng Zhu, et al. Study on bidirectional fluid-solid coupling characteristics of reactor coolant pump under steady-state condition [J]. Nuclear Engineering and Technology, 2019(51):1842-1852.

[2] Yunhua Li, Zhanling Ji, Liman Yang, et al. Thermal-fluid-structure coupling analysis for valve plate friction pair of axial piston pump in electrohydrostatic actuator (EHA) of aircraft $[\mathrm{J}]$. Applied Mathematical Modelling, 2017 (47): 839-858.

[3] Marcel Ilie. Fluid-structure interaction in turbulent flows; a CFD based aeroelastic algorithm using LES[J]. Applied Mathematics and Computation,2019 (342):309-321.

[4] Lingfeng Tang, Mingwei Liu, Feihong Ma. Thermosetting Coupling Analysis and Parameter Optimization of the Plastic Lining Pump Structure [J]. Advances in Materials Science and Engineering, 2019.

[5] R. Ramirez, E. Avila, L. Lopez, et al. CFD characterization and optimization of the cavitation phenomenon in dredging centrifugal pumps $[\mathrm{J}]$. Alexandria Engineering Journal,2020(59):291-309.

[6] Peng-Nan Sun, David Le Touz'e , Guillaume Oger, et al. An accurate FSI-SPH modeling of challenging fluid-structure interaction problems in two and three dimensions $[\mathrm{J}]$. Ocean Engineering ,2021 (221): 108552.

[7] T. Capurso, L. Bergamini, Torresi. Design and CFD performance analysis of a novel impeller for double suction centrifugal pumps[J]. Nuclear Engineering and Design ,2019 (341): $155-166$.

[8] M. Lorusso,T. Capurso,M. Torresi, et al. Efficient CFD evaluation of the NPSH for centrifugal 
pumps [J]. Nuclear Engineering and Design ,2017 (126): 778-785.

[9] Ashutosh.B.Deshmukh, Aditya.A.Lotake, Hrushikesh.N.Paricharak, et al. Comparative CFD Analysis of Mini Impeller Using Different Materials [J]. Materials Today: Proceedings ,2020 (24): $2115-2122$.

[10] George Dogkas, Emmanouil Rogdakis, Panagiotis Bitsikas. 3D CFD simulation of a Vuilleumier heat pump [J]. Applied Thermal Engineering, 2019 (153): 604-619.

[11] Nicola Aldi, Carlo Buratto, Michele Pinelli, et al. CFD Analysis of a non-Newtonian fluids processing pump [J]. Energy Procedia, 2016 (101): 742-749.

[12] Hanfei Chen, Peter Hofbauer, Jon P. Longtin. Multi-objective optimization of a free-piston Vuilleumier heat pump using a genetic algorithm [J]. Applied Thermal Engineering,2020(167):114767.

[13] K. Vinther, Rene J. Nielsen, Palle Andersen, et al. Optimization of interconnected absorption cycle heat pumps withmicro-genetic algorithms [J]. Journal of Process Control. 2017(53):26-36.

[14] Andrew Robison, Andrea Vacca. Multi-objective optimization of circular-toothed gerotors for kinematics and wear by genetic algorithm [J]. Mechanism and Machine Theory.2018(128):150-168.

[15] Duan Shengqiu, Yang Changming, Wang Guocheng. Optimal design of centrifugal pump impeller based on fluid- structure interaction and Kriging model [J]. Yangtze $R$ iver,2016,47(6):61-64.

[16] Wang Wei, Shi Weidong, Jiang Xiaoping. Optimization design of multistage centrifugal pump impeller by orthogonal experiment and CFD [J]. Jour of Drainage and Irrigation Machinery Engineering, 2016,03:1674-8530

[17] A.P. Masoumi, A.R. Tavakolpour-Saleh. Experimental assessment of damping and heat transfer coefficients in an active free piston Stirling engine using genetic algorithm [J]. Energy,2020(195):117064.

[18] Sreevatsa Anantharamu, Krishnan Mahesh. Response of a plate in turbulent channel flow: Analysis of fluid-solid coupling [J]. Journal of Fluids and Structures,2021(100):103173.

[19] Chen X, Schäfer M, Bothe D. Numerical Modelling of Viscoelastic Fluid-Structure Interaction and Its Application for a Valveless Micropump[M]// Numerical Mathematics and 
Advanced Applications - ENUMATH 2013. Springer International Publishing,2015:717-725.

[20] Gao Z, Liu J, Guo C, et al. The Strength Study of Thermal Power Unit Absorption Tower Desulphurization Pump Impeller Based on Fluid-Structure Interaction Calculation[M]// Proceedings of the 15th International Conference on Man-Machine-Environment System Engineering. 2015.

[21] Wei Lichao, song Wenwu, Shi Jianwei, et al. Numerical simulation and analysis of high speed centrifugal pump inlet flow based on CFD [J]. Journal of Engineering for Thermal Energy and Power, 2016(7):103-109.

[22] M. Specklin, P. Dubois, A. Albadawi, Y.M.C. Delauré. A full immersed boundary solution coupled to a Lattice-Boltzmann solver for multiple fluid-structure interactions in turbulent rotating flows [J]. Journal of Fluids and Structures. 2019(90):205-229.

[23] Silvia Bozzi, Simone Vesentini, Marco Santus, et al.Fluid dynamics characterization and thrombogenicity assessment of a levitating centrifugal pump with different impeller designs [J]. Medical Engineering and Physics,2020 (83): 26-33.

[24] Jamshid Piri, Bahareh Pirzadeh, Behrooz Keshtegar, et al. Reliability analysis of pumping station for sewage network usinghybrid neural networks - genetic algorithm and method of moment [J]. Process Safety and Environmental Protection,2021 (145) :39-51.

[25] Tong Chol Pak, Yong Chol Ri. Optimum designing of the vapor compression heat pump using system using genetic algorithm [J]. Applied Thermal Engineering,2019(147):492-500.

[26] Alperen Yildizeli, Sertac Cadirci. Multi-objective optimization of multiple impinging jet system through genetic algorithm[J]. International Journal of Heat and Mass Transfer,2020 (158): :119978.

[27] Serdar Ozyon. Optimal short-term operation of pumped-storage power plants with differential evolution algorithm [J]. Energy,2020 (194) :116866. 


\section{Declarations}

Availability of data and materials

All data generated or analysed during this study are included in this published article.

\section{Competing interests}

The authors declare that they have no conflicts of interest.

\section{Funding}

This article belongs to the major projects of the "The University Synergy Innovation Program of Anhui Province (GXXT-2019-004)." This article belongs to the project of the "Teaching Research Project of Anhui Education Department(2019jyxm0229)."

\section{Authors' contributions}

Lei Xiong contributed to the conception of the study and performed the data analyses and wrote the manuscript.

Lingfeng Tang and Bingxue Xu contributed significantly to analysis and manuscript preparation.

\section{Acknowledgements}

I would like to express my gratitude to all those who have helped me during the writing of this thesis. 